\title{
Anatomization of Mortality Trends in Under-Twelves in a Tertiary Hospital in Eastern Nigerian: A Cross Sectional Evaluation
}

\author{
Ogbonna BO ${ }^{1 *}$, Adijeh $\mathrm{CM}^{1}$, Onwuchuluba EE ${ }^{2}$, Eze $\mathrm{UIH}^{3}$, Onyeka T ${ }^{4}$, Uzodinma SU${ }^{1}$, Ofomata $\mathrm{PC}^{1}$, Iweh \\ $\mathrm{MI}^{1}$, Ajagu $\mathrm{N}^{1}$, Isidienu $\mathrm{CP}^{1}$, Ogbonna $\mathrm{AC}^{5}$ and Ejim $\mathrm{CE}^{6}$ \\ ${ }^{1}$ Department of Clinical Pharmacy and Pharmacy Management, Faculty of Pharmaceutical Sciences, Nnamdi Azikiwe University, Awka, \\ Nigeria
}

${ }^{2}$ Department of Clinical Pharmacy and Bio-Pharmacy, Faculty of Pharmacy, University of Lagos, Lagos State, Nigeria

${ }^{3}$ Department of Clinical Pharmacy and Bio-Pharmacy, Faculty of Pharmacy, Olabisi Onabanjo University, Shagamu, Nigeria

${ }^{4}$ Department of Anesthesia University of Nigeria Teaching Hospital Ituku-Ozalla, Enugu, Nigeria

${ }^{5}$ Department of Anesthesia, ESUT Teaching Hospital, Enugu, Nigeria

${ }^{6}$ Department of Clinical Pharmacy and Pharmacy Management, Faculty of Pharmacy, Enugu State University of Science and Technology, Enugu, Nigeria

*Corresponding author: Ogbonna BO, Department of Clinical Pharmacy and Pharmacy Management, Faculty of Pharmaceutical Sciences, Nnamdi Azikiwe University, Awka, Nigeria

\begin{abstract}
ARTICLE INFO
Received: 豐 May 29, 2019

Published: 䦥 June 07, 2019

Citation: Ogbonna BO, Adijeh CM, Onwuchuluba EE, Eze UIH, Onyeka T, Uzodinma SU, Ofomata PC, Iweh MI, Ajagu $\mathrm{N}$, Isidienu CP, Ogbonna AC, Ejim CE. Anatomization of Mortality Trends in Under-Twelves in a Tertiary Hospital in Eastern Nigerian: A Cross Sectional Evaluation. Biomed J Sci \& Tech Res 18(4)2019. BJSTR. MS.ID.003188.
\end{abstract}

Keywords: Mortality; Under-12; Child health; Maternal health; Death register; Morbidity

Abbreviations: NAUTH: Nnamdi Azikiwe University Teaching Hospital; WHO: World Health Organization; UNICEF: United Nations Children's Fund; SCBU: Special Care Baby Unit; CHER: Children Emergency Room; PMW: Pediatric Medical Ward; PSW: Pediatric Surgical Ward; A/E: Accident and Emergency; ICU: Intensive Care Unit; PEW: Pediatric Extension Ward; IMR: Infant Mortality Rate, LMICs: Lowand-Middle-Income Countries; MDG: Millennium Development Goals; SDG: Sustainable Development Goals
ABSTRACT

Background: The childhood age group is a special population that needs critical and special care. The increase in death tolls in children globally, owing majorly to preventable and treatable causes and diseases are a burden and require urgent and immediate attention and action to ensure sustainable progress towards achieving child survival goals. This study assessed mortality pattern of under-12 and discussed the associated factors.

Methods: A cross-sectional retrospective descriptive study of 4 years which spanned from January 2014 to December 2017 was carried out on the records of dead children who were 12 years and below using the death register at the health care facility. The data were summarized with descriptive and inferential statistics.

Results: A total of 1004 under-12 deaths were recorded: 255, 218, 291 and 240 deaths occurred in 2014, 2015, 2016 and 2017. Children between ages 0-1 had the highest death record 819 (81.6\%). A higher death rate was observed among male children 569.0 (56.5\%) compared to female children 438.0 (43.5\%). Diagnosed diseases which led to their death ranged from sepsis, birth asphyxia, malaria, gastrointestinal disorders, respiratory/ pulmonary disorders, prematurity, anemia, and genetic disorders. Death due to sepsis, septicemia and septic shock had the highest percentage with frequency and percentage prevalence of 159.0 (15.8\%). while birth/perinatal/neonatal asphyxia, prematurity was high.

Conclusion: Male children below one year were the most affected. Sepsis, septicemia, septic shock; prematurity/preterm, and Birth/perinatal/neonatal asphyxia, birth trauma and seizures were the leading causes of death in the population. The highest death was recorded at the Special Care Baby Unit (SCBU), and Children Emergency Room (CHER). Study suggests that the leading causes of death among children in this study are still prevalent in sub-Saharan Africa. 


\section{Introduction}

\section{Background of the Study}

The WHO Convention on the rights of the child defines a child as "a person below the age of 18 years unless the laws of a particular country set the legal age for adulthood younger" [1]. Under-12 mortality is the probability of a newborn baby dying between birth and exactly 12 years of age. Child mortality, also known as child death, refers to the death of children under the age of 14 and encompasses neonatal mortality, under-5 mortality, and mortality of children aged 5-14. There is paucity of information about the direct causes of child mortality in developing countries. Child survival remains an urgent concern and as such should not be treated with triviality. Child mortality is a sensitive indicator of a country's development and a representation of its priorities and values [2-5]. It is unacceptable that about 16,000 children still die every single day - equivalent to 11 deaths occurring every minute. This increasing death toll has a significant effect on the economy of a nation as potential human resources are lost at such tender ages. Socioeconomic determinants, environmental determinants, nutritional status, personal illness control and growth faltering are some of the risk factors known to have a strong relation to child mortality.

Children who die within the first 28 days of life often do so as a result of diseases and conditions that are readily preventable or treatable with proven, cost-effective interventions. Globally, 3 in 4 neonatal deaths are caused by preterm birth complications, complications during labor and delivery (intrapartum-related complications), and sepsis [6,7]. It becomes critically important to accelerate progress in saving the lives of newborns with simple, cost-effective interventions as well as quality care before, during and immediately after birth. This necessitates an evaluation of mortality trend in this population to identify and analyze the risk factors of death as timely and accurate information on the causes of deaths in children less than 5 years old helps in guiding the efforts made to improve child health as a proactive and preventive tool for intervention $[8,9]$. Data on morbidity and mortality are essential for assessing population health status and disease burden. Valid information on causes of death is an essential tool for the development of national and international health policies for prevention, better management, and control of diseases and complication [10,11]. Most mortality information of countries, communities and facilities are readily available in demographic and health surveys, censuses, hospital medical records among others [12]. Retrospective reviews of these data sources have been the trend of most studies $[3,13,14]$. This study provided information on the mortality trends in under-12 and explored the associated factors.

\section{Methods}

\section{Study Area}

The study area was Anambra State, an inland state located in the south-central area of southeastern Nigeria. Its capital is Awka. Anambra state boasts of an undulating landscape with tall trees and vegetation and also mineral resources. It is bordered to the north by Kogi State, to the south by Imo State and Rivers State, to the east by Enugu State and to the west by Delta State. Together with Imo State, it forms the heartland of Igbo land. Nnewi is the second largest city in Anambra State located east of the Niger River and about 22 kilometers southeast of Onitsha. It is comprised of Nnewi North commonly referred to as Nnewi Central; where the tertiary health care facility is located; and Nnewi south.

\section{Study Design}

The study was a cross-sectional retrospective study which utilized records and documentation of the death register and post-mortem reports. Documentations used covered four year period which spanned from January 2014 to December 2017 predominantly from the pediatric department not excluding other departments of the hospital where the population group under study were managed. A detailed collection of data was done and systematically categorized into age, sex, clinic, definitive diagnosis, risk factors, the frequency of each factor, yearly occurrence. This provided an insight into the leading cause of mortality in pediatrics managed in various clinics of the hospital.

\section{Participants}

Dead under-12 aged children's medical records from the death register, mortality record and medical records.

Variables

Age, sex, diagnosis/risk factors, unit,

\section{Study Setting}

The study was conducted in a tertiary health care facility in Anambra State, South East Nigeria having most specialties in medicine. The facility is The Nnamdi Azikiwe University Teaching Hospital (NAUTH), Nnewi, providing health care services to the teeming population of Anambra State and environs.

Study/Sample size: All the eligible data which met the inclusion criteria were collected from the register. A total of 1004 eligible data was obtained and all were used and properly analyzed to increase reliability.

\section{Bias}

Every form of identification was excluded from the data

Ethical Consideration: Before commencement of the above study, ethical approval for the study protocol was obtained from the Research and Ethics committee of the tertiary health care facility.

\section{Inclusion Criteria:}

a. All registered medical records of under-twelve death cases from January 2014 to December 2017.

b. All hospitalized and outpatient registered death cases for this population.

\section{Exclusion Criteria:}

a. All registered under-twelve death outside the period from January 2014 to December 2017. 
b. All none- registered death cases pertaining to the population under study

c. All death cases of children beyond twelve years of age.

\section{Data Collection}

Data on mortality of under-12 children was collected using the patient's medical records and death register at the records section of the Pediatric Department. A detailed data collection was done using structured data collection form and categorized according to the various age distribution, gender distribution, clinics and the health condition implicated in each death case from the period of January 2014 to December 2017. The data was and entered into the data collection forms in a presentable manner. This provided an insight into the leading risk factor of mortality and its frequency between the periods.

\section{Data Management}

All data was collated and entered into Microsoft Excel, 2010 spread sheet and cleansed. Thereafter, data was summarized with descriptive statistics. Level of association between death prevalence and various parameters (clinic, age and sex and year) was carried out using Chi-square test.

\section{Results}

Test of association using Chi-square showed no statistically significant association ( $\mathrm{P}>0.05: \mathrm{p}=0.999, \chi 2=5.908$ ) between age distribution of death record among the four years. Table 1 shows the distribution of children mortality with respect to gender. There was a higher death rate among male children than female children in four years. Generally, out of 1004 mortality record, the majority (569.0, 56.5\%) were males than females (438.0, 43.5\%). Chisquare test revealed a statistically significant association $(\mathrm{P}<0.05: \mathrm{p}$ $=0.0005, \chi 2=65.004$ ) between the number of the death record for males and females in 2014, 2015, 2016 and 2017. Similar mortality trend was observed among the 11 clinics from 2014 to 2017 in Tables 2 \& 3. Descriptive statistics revealed that Special Care Baby Unit (SCBU) and CHER (Children Emergency Room) were the two major clinics with highest death records.

Table 1: Distribution of death among children of 12 years and below in Nnamdi Azikiwe Teaching Hospital.

\begin{tabular}{|l|c|c|c|c|c|c|}
\hline \multirow{2}{*}{ Year } & \multicolumn{3}{|c|}{ Age } & \multicolumn{3}{c|}{ Gender } \\
\cline { 2 - 7 } & Age range & $\mathbf{n}$ & $\mathbf{( \% )}$ & Gender & $\mathbf{n}$ & $\mathbf{( \% )}$ \\
\hline \multirow{5}{*}{$2014, \mathrm{n}=255$} & $0-1$ & 214 & 83.9 & Male & 150 & 58.8 \\
\cline { 2 - 7 } & $1.1-2.0$ & 13 & 5.1 & Female & 105 & 41.2 \\
\cline { 2 - 7 } & $2.1-4.0$ & 6 & 2.4 & & & \\
\cline { 2 - 7 } & $4.1-6.0$ & 8 & 3.1 & & & \\
\cline { 2 - 7 } & $6.1-8.0$ & 5 & 2 & & & \\
\cline { 2 - 7 } & $8.1-10.0$ & 7 & 2.7 & & & \\
\cline { 2 - 7 } & $10.1-12.0$ & 2 & 0.8 & & & \\
\hline
\end{tabular}

\begin{tabular}{|c|c|c|c|c|c|c|}
\hline \multirow{7}{*}{$2015, n=218$} & $0-1.0$ & 183 & 83.9 & Male & 117 & 53.7 \\
\hline & $1.1-2.0$ & 12 & 5.5 & Female & 101 & 46.3 \\
\hline & $2.1-4.0$ & 5 & 2.3 & & & \\
\hline & $4.1-6.0$ & 4 & 1.8 & & & \\
\hline & $6.1-8.0$ & 4 & 1.8 & & & \\
\hline & $8.1-10.0$ & 4 & 1.8 & & & \\
\hline & $10.1-12.0$ & 6 & 2.8 & & & \\
\hline \multirow{7}{*}{$\begin{array}{c}2016, n= \\
291\end{array}$} & $0-1.0$ & 237 & 81.4 & Male & 167 & 56.4 \\
\hline & $1.1-2.0$ & 18 & 6.4 & Female & 127 & 43.6 \\
\hline & $2.1-4.0$ & 11 & 3.6 & & & \\
\hline & $4.1-6.0$ & 7 & 2.4 & & & \\
\hline & $6.1-8.0$ & 8 & 2.7 & & & \\
\hline & $8.1-10.0$ & 7 & 2.4 & & & \\
\hline & $10.1-12.0$ & 3 & 1 & & & \\
\hline \multirow{7}{*}{$2017, \mathrm{n}=240$} & $0-1.0$ & 185 & 77.1 & Male & 135 & 56.3 \\
\hline & $1.1-2.0$ & 21 & 8.8 & Female & 105 & 43.8 \\
\hline & $2.1-4.0$ & 8 & 3.3 & & & \\
\hline & $4.1-6.0$ & 7 & 2.9 & & & \\
\hline & $6.1-8.0$ & 5 & 2.1 & & & \\
\hline & $8.1-10.0$ & 6 & 2.5 & & & \\
\hline & $10.1-12.0$ & 8 & 3.3 & & & \\
\hline \multirow[t]{3}{*}{ Total } & & 1004 & 100 & Male & 569 & 56.5 \\
\hline & & & & Female & 438 & 43.5 \\
\hline & & & & Total & 1004 & 100 \\
\hline
\end{tabular}

Where the $n=$ total number of deaths in a year.

Table 2: Distribution trend of deaths records among various Clinics in Nnamdi Azikiwe Teaching.

\begin{tabular}{|c|c|c|c|c|c|c|c|c|}
\hline Units & $\mathbf{n}$ & (\%) & $\mathbf{n}$ & (\%) & $\mathbf{n}$ & (\%) & $\mathbf{n}$ & (\%) \\
\hline Year & \multicolumn{2}{|c|}{2017} & \multicolumn{2}{|c|}{2016} & \multicolumn{2}{|c|}{2015} & \multicolumn{2}{|c|}{2014} \\
\hline SCBU & 79 & 32.9 & 105 & 36.1 & 129 & 59.3 & 143 & 56.1 \\
\hline ICU & 8 & 3.3 & 9 & 3.1 & 3 & 1.4 & 8 & 3.1 \\
\hline CHER & 96 & 40.4 & 113 & 38.8 & 65 & 29.8 & 76 & 29.8 \\
\hline PSW & 10 & 4.2 & 8 & 2.7 & 2 & 0.9 & 3 & 1.2 \\
\hline PEW & 26 & 10.8 & 19 & 6.5 & 7 & 3.2 & 12 & 4.7 \\
\hline PMW & 15 & 6.3 & 27 & 9.4 & 4 & 1.8 & 11 & 4.3 \\
\hline A/E & 5 & 2.1 & 9 & 3.1 & 2 & 0.9 & 1 & 0.4 \\
\hline FSW & 0 & 0 & 0 & 0 & 2 & 0.9 & 0 & 0 \\
\hline MSW & 0 & 0 & 0 & 0 & 2 & 0.9 & 0 & 0 \\
\hline FMW & 0 & 0 & 1 & 0.3 & 2 & 0.9 & 1 & 0.4 \\
\hline MM & 1 & 0 & 0 & 0 & 0 & 0 & 0 & 0 \\
\hline Others & 0 & 0 & 0 & 0 & 0 & 0 & 0 & 0 \\
\hline Total & 240 & 100 & 291 & 100 & 218 & 100 & 255 & 100 \\
\hline
\end{tabular}


Table 3: Risk factors responsible for death among children in four years in Nnamdi Azikiwe Teaching Hospital.

\begin{tabular}{|c|c|c|c|c|c|c|}
\hline \multirow{2}{*}{ S/no } & \multirow{2}{*}{ Risk factors } & 2014 & 2015 & 2016 & 2017 & Total \\
\hline & & n (\%) & n (\%) & n (\%) & n (\%) & n (\%) \\
\hline 1 & $\begin{array}{c}\text { Birth/perinatal/neonatal asphyxia, birth trauma } \\
\text { and seizures }\end{array}$ & $45.0(17.6)$ & $33.0(15.1)$ & $34.0(11.7)$ & $25.0(10.4)$ & $137.0(13.6)$ \\
\hline 2 & Neonatal jaundice & $7.0(2.7)$ & $9.0(4.1)$ & $3.0(1.0)$ & $1.0(0.4)$ & $20.0(2.0)$ \\
\hline 3 & Neonatal sepsis & $12.0(4.7)$ & $5.0(2.3)$ & $4.0(1.4)$ & $12.0(5.0)$ & $33.0(3.3)$ \\
\hline 4 & LBW/VLBW & $3.0(1.2)$ & $6.0(2.8)$ & $2.0(0.7)$ & $5.0(2.1)$ & $16.0(1.6)$ \\
\hline 5 & ELBW & $2.0(0.8)$ & $0.0(0.0)$ & $1.0(0.3)$ & $0.0(0.0)$ & $3.0(0.3)$ \\
\hline 6 & Prematurity/preterm & $38.0(14.9)$ & $40.0(18.3)$ & $41.0(14.1)$ & $17.0(7.1)$ & $136.0(13.5)$ \\
\hline 7 & Preterm with LBW/VLBW & $7.0(2.7)$ & $2.0(0.9)$ & $5.0(1.7)$ & $10.0(4.2)$ & $24.0(2.4)$ \\
\hline 8 & Genetic disorder \& congenital anomalies & $8.0(3.1)$ & $10.0(4.6)$ & $2.0(0.7)$ & $6.0(2.5)$ & $26.0(2.6)$ \\
\hline 9 & Sepsis, septicemia \& septic shock & $35.0(13.7)$ & $20.0(9.2)$ & $62.0(21.3)$ & $42.0(17.5)$ & $159.0(15.8)$ \\
\hline 10 & Malaria \& its complications & $6.0(2.4)$ & $11.0(5.0)$ & $7.0(2.4)$ & $4.0(1.7)$ & $28.0(2.8)$ \\
\hline 11 & RVD (Retroviral diseases) & $4.0(1.6)$ & $2.0(0.9)$ & $2.0(0.7)$ & $5.0(2.1)$ & $13.0(1.3)$ \\
\hline 12 & Urological disorders & $1.0(0.4)$ & $2.0(0.9)$ & 0 & $6.0(2.6)$ & $9.0(0.9)$ \\
\hline 13 & GIT disorders & $15.0(5.9)$ & $12.0(5.5)$ & $29.0(10.0)$ & $21.0(8.8)$ & $77.0(7.7)$ \\
\hline 14 & Dietary disorders & $2.0(0.8)$ & $2.0(0.9)$ & $7.0(2.4)$ & $4.0(1.7)$ & $15.0(1.5)$ \\
\hline 15 & DOA (Dead on arrival) & $2.0(0.8)$ & $4.0(1.8)$ & $2.0(0.7)$ & $2.0(0.8)$ & $10.0(1.0)$ \\
\hline 16 & Respiratory/Pulmonary disorders \& diseases & $11.0(4.3)$ & $16.0(7.3)$ & $12.0(4.1)$ & $15.0(6.3)$ & $54.0(5.4)$ \\
\hline 17 & Nephropathy/kidney disorders & $4.0(1.6)$ & $3.0(1.4)$ & $4.0(1.4)$ & $2.0(0.8)$ & $13.0(1.3)$ \\
\hline 18 & Cardiovascular diseases & $8.0(3.1)$ & $9.0(4.1)$ & $16.0(5.5)$ & $4.0(1.7)$ & $37.0(3.7)$ \\
\hline 19 & Anemia & $1.0(0.4)$ & $3.0(1.4)$ & $3.0(1.0)$ & $6.0(2.5)$ & $13.0(1.3)$ \\
\hline 20 & CNS disorders \& seizures & $15.0(5.9)$ & $5.0(2.3)$ & $10.0(3.4)$ & $19.0(7.9)$ & $49.0(4.9)$ \\
\hline 21 & Liver diseases & $3.0(1.2)$ & $1.0(0.5)$ & $4.0(1.4)$ & $2.0(0.8)$ & $10.0(1.0)$ \\
\hline 22 & Injuries and burns & $4.0(1.6)$ & $5.0(2.3)$ & $9.0(3.1)$ & $11.0(4.6)$ & $29.0(2.9)$ \\
\hline 23 & Shocks & $3.0(1.2)$ & $2.0(0.9)$ & $2.0(0.7)$ & $1.0(0.4)$ & $8.0(0.8)$ \\
\hline 24 & Cancers \& tumors & $5.0(2.0)$ & $4.0(1.8)$ & $11.0(3.8)$ & $7.0(2.9)$ & $27.0(2.7)$ \\
\hline 25 & Unknown/unidentified causes & $4.0(1.6)$ & $3.0(1.4)$ & $4.0(1.4)$ & $3.0(1.3)$ & $14.0(1.4)$ \\
\hline 26 & Other causes & $10.0(3.9)$ & $9.0(4.1)$ & $15.0(5.2)$ & $10.0(4.2)$ & $44.0(4.4)$ \\
\hline Total & & $255.0(100.0)$ & $218.0(100.0)$ & $291.0(100.0)$ & $240.0(100.0)$ & $1004.0(100.0)$ \\
\hline
\end{tabular}

These were followed by PSW (Pediatric Surgical Ward), PEW (Pediatric Extension Ward), PMW (Pediatric Medical Ward) and Accident and Emergency (A/E). Other clinics had little or no death records. Chi-square test revealed that death record among the 11 clinics was statistically significantly associated with years $(\mathrm{P}<0.05: \mathrm{p}=0.039, \chi 2=41.270)$. In other words, the level of death distribution in the 11 clinics in four years varied significantly. Chisquare test revealed that the distribution of death record among the four years were not statistically significant $(P>0.05$ : $p=0.891, \chi 2=$ 60.347). Test statistics results revealed a high infant mortality rate which included perinatal and neonatal mortality with the highest mortality among children born between 0-1 years as compared to other age categories. However, there was no significant level of association between age distribution of death record among the four years with a P-value greater than $0.05,(p=0.999)$.

\section{Discussion}

Sex and gender differentials in survival result from a complex interplay of biological and behavioral factors that impact mortality at different stages in the life course. In countries with very low mortality, females have lower mortality than males at all ages. In the four years, the majority of the deaths recorded from the study were among the male children (569.0,56.5\%) as compared to the female children (438.0, 43.5\%). Hence, more than half of the deaths recorded were found among the male gender. Also, there was an observed significance level of association between the number of the death record for males and females in the respective years. This is shown by a P-value of $\mathrm{p}=0.0005(\mathrm{P}<0.05)$. The children were managed in various clinics of the hospitals ranging from special care baby unit (SCBU), children emergency room (CHER), 
pediatric medical ward (PMW), pediatric surgical ward (PSW), A/E (Accident and Emergency), intensive care unit (ICU), and pediatric extension ward (PEW). Of all the 11 clinics where these children were managed, SCBU and CHER had the highest death records. The level of death distribution in the various clinics in four years varied significantly.

Most under-five deaths and in general child mortality, are caused by diseases that are readily preventable or treatable with proven, cost-effective interventions. Infectious diseases and neonatal complications are responsible for the vast majority of under-five deaths globally. The probability of deaths among children aged 5-14 was $7.5(7.2,8.3)$ deaths per 1,000 children aged 5 in 2016 substantially lower than among younger children. Still, 1 $(0.9,1.1)$ million children aged $5-14$ died in 2016. This is equivalent to 3,000 children in this age group dying every day. Among children aged 5-14, communicable diseases are a less prominent cause of death than among younger children, while other causes including injuries and non-communicable diseases become important Among children aged 5-9 years and younger adolescents aged 1014 years, communicable diseases are a less prominent cause of death than among younger children, while other causes become important. For instance, injuries account for more than a quarter of the deaths among this age group, non-communicable diseases for about another quarter and infectious diseases and other communicable diseases, perinatal and nutritional causes for about half of the deaths. Drowning and road injuries alone account for10 percent of all deaths in this age group [15].

Despite the substantial progress in reducing child deaths, children from poorer areas or households remain disproportionately vulnerable. It is critical to address these inequities to further accelerate the pace of progress to fulfill the promise to children. This goes to implicate poverty as an important risk factor to child mortality. The risk implicated in under-12 mortality from the study included: birth/perinatal/neonatal asphyxia and birth trauma and seizures, neonatal jaundice, neonatal sepsis, intrapartum complications, prematurity, low birth weight (LBW), sepsis, malaria, gastrointestinal disorders, respiratory/pulmonary disorders, cardiovascular diseases, liver diseases, retroviral diseases, congenital anomalies, etc. Gastrointestinal disorders implicated include intestinal obstruction, peptic ulcer disease (PUD), gastroenteritis, enterocolitis, Respiratory/pulmonary disorders implicated included: pneumonitis, bronchopneumonia, tracheoesophageal fistula, pulmonary tuberculosis among others. Gastroschisis, trisomy' 21, down syndrome etc. constitute genetic disorders. Also, dietary disorders such as protein-energy malnutrition, kwashiorkor, marasmus, etc. were also risk factors that predisposed these populations to death.

Of all these causes, extreme low birth weight (ELBW) had the lowest risk of death. There was no significant level of association between the number of death records and the various risk factors to mortality evidenced by a P-value of 0.891 . Maternal health is as important as child health as it has a direct impact on child health and mortality. The United Nations Children's Emergency Fund (UNICEF) identifies that children are at a greater risk of dying before age five if they are born in rural areas, among the poor, or to a mother deprived of basic education. The World Health Organization recognizes reproductive health as inclusive of "the right of access to appropriate health-care services that will enable women to go safely through pregnancy and childbirth and provide couples with the best chance of having a healthy infant $[16,17]$. Maternal factors such as maternal education, a birth interval greater than 24 months, adequate breastfeeding are significant protective factors for child survival. Maternal education plays a vital role in the utilization of antenatal care [18-23]. In line with the general perception and a well-documented fact, the effects of breastfeeding and birth interval of more than 2 years are significant protective factors [24-27].

Infants not exclusively breastfed are 15 times more likely to die from pneumonia and 11 times more likely to die from diarrhea than those who are exclusively breastfed [28]. The UNICEF report projects that if all birth to pregnancy intervals were 3 years, approximately 1.6 million under-five deaths could be prevented annually [29]. Efforts should continue to delay the next pregnancy. In addition, maternal age, i.e., the age of the mother at their first birth is a key correlate of child health outcomes. Teen mothers have children with the worst health outcomes and children of mothers who have their first birth in their early 20s are also at risk of poor health outcomes compared to first-time mothers in their late $20 \mathrm{~s}$. Raj et al showed that children born to mothers in India who were married below the age of 18 were at a higher risk of stunting and underweight as compared to children of women who had married at 18 or older. The effect of the young age of the mother at first birth on poor child health outcomes reflects the interplay of biological and social factors [30-35]. Other factors which come to play include proper sanitation and hygiene, nutrition, etc. Poor sanitation and hygiene contribute to fecal pathogens in the environment which, when ingested through contaminated food and water lead to disease.

Under-nutrition has a direct effect on child mortality as it compromises the immune function and increases susceptibility to infectious disease. It is an underlying cause of more than 3 million child deaths per year and is also a consequence of poor health, as infectious diseases increase energy requirements and often reduce appetite and nutrient absorption [36-38]. Optimal maternal nutrition is an important contributory factor to the survival of both the mother and child and promotes women's overall health, productivity, and well-being. Two critical pathways through which women's nutrition affects survival outcomes include anemia and calcium deficiency. Pregnancy increases the risk of maternal anemia as the maternal iron requirements increase to support maternal and fetal needs. Epidemiological studies have linked low calcium intake to gestational hypertension which could lead to preeclampsia and eclampsia, now the second most important cause of maternal mortality worldwide [39]. The impact of institutional 
or nosocomial and community-acquired infections cannot be undermined [40-42].

\section{Conclusion}

In line with similar studies, there exists a trend of mortality in children with respect to age and gender. These mortality cases are attributable to various factors which have been identified as well as some unknown or unidentified causes (which could be a lag in proper documentation). Mortality can thus be said to arise from the interplay of various factors, hence, hospital-based records to a considerable extent provide relevant information on the trends as well as factors implicated in the mortality trends. This emphasizes the importance of maternal and child health in an economy.

Limitations of the study: Incomplete documentation by the health facility as some diagnosis that leads to death was not stated hence making it difficult to identify the cause of death in such children. The possibility of incomplete documentation and retrieval of data from the primary data sources cannot be completely ruled out.

\section{Declarations}

Ethics approval and consent to participate: An ethical approval was obtained from the Research and Ethics Committee of Nnamdi Azikiwe University Teaching Hospital, Nnewi Anambra State, Nigeria with Reference Number: NAUTH/CS/66/ VOL. 11/028/2018/008. Consent does not apply since we used records of dead patients without their means of identification.

\section{Consent for publication: Does not apply}

Availability of data and material: All data generated or analyzed during this study are included in this published article

Competing interests: The authors have none to declare

\section{Funding}

There was no funding obtained for the study

\section{Authors' contributions}

OBO designed the study, OAC, OT, ON, OEE, EUHI,ECE, and OAC assisted in data collection, $\mathrm{OBO}$ and $\mathrm{OAC}$ analyzed and interpreted data, BO, AC, OT, ON, EE, EUHI, IMI, ICP, AN, USU, OPC, and OAC contributed in writing. OBO did the final proofing and edited the work.

\section{Acknowledgment}

We want to appreciate all the staff of medical records at NAUTH who assisted in no mean way of providing us with all the necessary records and timely too.

\section{References}

1. Nwafor CC, Abali C, Nnoli MA (2014) Childhood Mortality in Federal Medical Centre Umuahia, South Eastern Nigeria. Oman Med J 29(5): 320-324.

2. Nasejje JB, Henry G Mwambi H, Thomas NO Achia (2015) Understanding the determinants of under-five child mortality in Uganda including the estimation of unobserved household and community effects using both frequentist and Bayesian survival analysis approaches. BMC Public Health 15: 1003.

3. Mdala JF, Mash R (2015) Causes of mortality and associated modifiable health care factors for children $(<5$-years) admitted at Onandjokwe Hospital, Namibia. African Journal of Primary Health Care and Family Medicine 7(1).

4. (2017) United Nations. Mortality Report. The UN inter-agency group for child mortality Estimation; Levels and Trends in Child Mortality: Report 2017. New York: UNICEF.

5. Wardlaw T, You D, Hug L, Amouzou A, Newby H (2014) UNICEF Report: Enormous progress in child survival but a greater focus on newborns urgently needed. Reprod Health 11(1): 82.

6. Bryce J, Black RE, Victoria CG (2013) Millenium Development Goals 4 and 5: progress and challenges. BMC Med 11: 225.

7. Ezeh OK, Agol KE, Dibley MJ, Hall J, Page AN (2015) Determinants of Neonatal Mortality in Nigeria: Evidence from the 2008 demographic and health survey. BMC public health14: 521.

8. Gbenga K, Victor A, Olalekan U (2012) Risk factors and a predictive model for under-five mortality in Nigeria: Evidence from Nigeria demographic and health survey. BMC pregnancy and childbirth 12: 10.

9. Hobcraft JN, McDonald JW, Rutstein SO (1985) Demographic determinants of infant andearly child mortality. A comparative analysis population study 39(3): 363-365.

10. Ekow W, Donkor, S (2016) University of Ghana (10551459).

11. Ogbonna BO (2015) Postmortem Evaluation of Mortality Trends in Deceased Type 2 Diabetes Mellitus Patients in two Tertiary Teaching Hospitals in Southeast Nigeria. Elixir Pharmacy 88: 36309-36312.

12. (2011) Bangladesh Demographic and health survey. National Institute of population research and training (NIPORT) Dhaka, Bangladesh, MEASURE DHS, ICF International, Calverton, Maryland, USA.

13. Say L, Chou D, Gemmill A, Tunçalp Ö, Moller AB, et al. (2014) Global causes of maternal death: a WHO systematic analysis. The lancet global health 2(6): 323-333.

14. (2011) World Health Organization. Report on the burden of endemic health care-associated infection worldwide.

15. Tabutin D, Willems M (1995) World during the 1970s and 1980s, Excess Female Child Mortality in the Developing World during the 1970s and 1980s. Population bulletin of the United Nations 39(39): 45-78.

16. Katz J, Lee AC, Kozuki N, Lawn JE, Cousens S, et al. (2013) Mortality risk in preterm and small-for-gestational-age infants in low income and middle-income countries: a pooled country analysis. Lancet 382(9890): 417-425.

17. (2013) Levels, and trends in child mortality, UNICEF, WHO.

18. Glasier A, Gülmezoglu AM, Schmid GP, Moreno CG, Van Look PF (2006) Sexual and reproductive health: a matter of life and death. The Lancet 368(9547): 1595-1607.

19. Kumar D, Aggarwal A, Gomber S (2010) Immunization status of children admitted to a tertiary-care hospital of north India: reasons for partial immunization or non-immunization. J Health Popul Nutr 28(3): 300304.

20. Chalasani S (2012) Understanding wealth-based inequalities in child health in India: a decomposition approach. Soc Sci Med 75(12): 21602169.

21. Ghosh S (1988) Looking beyond the child. Indian J Pediatr 55: 879-881.

22. Claeson M, Eduard BR, Tazim M, Pathmanathan I (2000) Reducing child mortality in India in the new millennium. Bull WHO 78(10): 1193-1199.

23. Osei Kwaky K, Otupiri E, Owusu DE, Browne ENL, Adju M (2010) Determinants of Under-Five Mortality in Builsa District, Upper East Region, Ghana. Journal of Science and Technology (Ghana) 30(1). 
24. (2014) Levels and Trends in Child Mortality. The UN inter-agency group for child mortality. New York: UNICEF.

25. Robert BE, Saul MS, Jennifer B (2003) Where and why 10 million children dying every year: Child Survival. Lancet 361(19376): 2226-2233.

26. Fleischmann C, Scherag A, Adhikari NK, Hartog CS, Tsaganos T, et al. (2016) Assessment of Global incidence and Mortality of hospital-based sepsis. Current estimates and limitations. Am J Respir Crit Care Med 193(3): 259-272.

27. (2005) WHO. The world health report: make every mother and child count. Geneva, Switzerland.

28. Singhi S, Gupta G, Jain V (2004) Comparison of pediatric emergency patients in a tertiary care hospital vs. community hospital. Indian Pediatrics 41(1): 67-72.

29. (2014) UNICEF: Committing to child survival: A promise renewed progress report 2014. New York: UNICEF.

30. (2017) Levels and Trends in Child Mortality. The UN inter-agency group for child mortality Estimation. New York: UNICEF.

31. Raj A, Saggurti N, Winter M, Labonte A, Decker MR, et al. (2010) The effect of maternal child marriage on morbidity and mortality of children under 5 in India: Cross sectional study of a nationally representative sample. BMJ 340: b4258.

32. Glass RI, Guttmacher AE, Black RE (2012) Ending preventable child death in a generation. JAMA 308(2): 141-142.

33. Nour NM (2009) Child Marriage: A silent health and human rights issue. Rev Obstet Gynecol 2(1): 51-56.

\section{ISSN: 2574-1241}

DOI: 10.26717/BJSTR.2019.18.003188

Ogbonna B0. Biomed J Sci \& Tech Res

(C) This work is licensed under Creative

Submission Link: https://biomedres.us/submit-manuscript.php
34. Raj A, Saggurti N, Balaiah D, Silverman JG (2009) Prevalence of child marriage and its effect on fertility and fertility-control outcomes of young women in India: A cross-sectional, observational study. Lancet 373(9678): 1883-1889.

35. (2018) World Health Organization. Adolescent pregnancy.

36. Yogita PP, Dinesh JB (2015) An epidemiological study of child marriages in a rural community of Gujarat. Indian J of Comm Med 40(4): 246-251.

37. Rahman MM, Islam M, Ali MK (2005) Effects of demographic characteristics on infant and child mortality. A case study of Rajshahi District, Bangladesh. Journal of population 12(2): 161-173

38. Lasme E, Charles J (2013) Determinants of mortality in children under five in Ivory Coast. European Scientific Journal 9: 139-150.

39. Bhutta ZA, Ahmed T, Black RE, Cousens S, Dewey K, et al. (2008) What works? Interventions for maternal and child under nutrition and survival. Lancet 371(9610): 417-440.

40. Black RE, Allen LH, Bhutta ZA, Laura EC, Mercedes de O (2008) Maternal and child undernutrition: global and regional exposures and health consequences. Lancet 371(9608): 243-260.

41. Mathers CD, Ma fat D, In oue M, Rao C, Lopez AD (2005) Counting the dead and what they die from: an assessment of the global status of cause of death data. Bulletin of the world health organization 83(3): 171-177.

42. Waldron, Ingrid (1998) Sex differences in infant and early childhood mortality: Major cause of death and possible biological causes. In too young to die: Genes or gender? pp. 64-83.

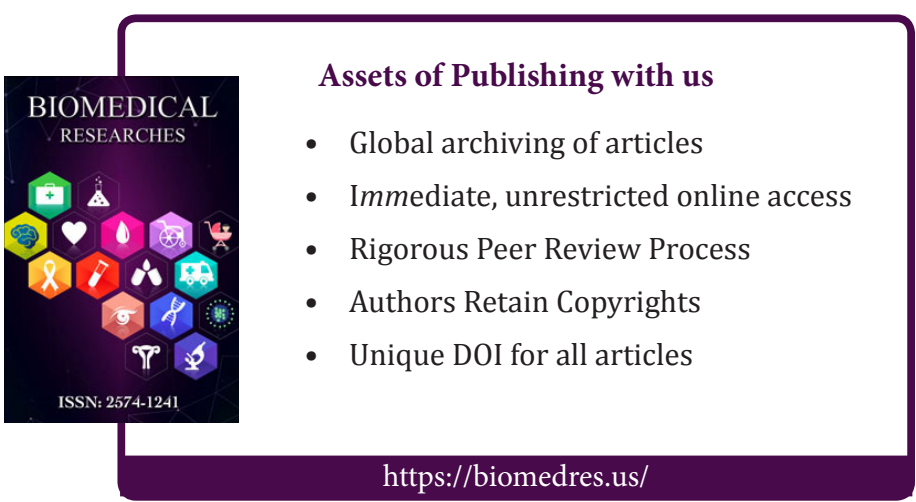

